\title{
学習制御方式を用いたモデル規範形適応制御系の 構成法
}

\author{
大場 和 久 $^{* *}$. 点 竹 俊 昭 ${ }^{* *}$-井上 和 夫 $^{* * *}$
}

\section{A Constitution of a Model Reference Adaptive Control System by Learning Control Method*}

Kazuhisa OвA ${ }^{* *}$, Toshiaki Kuretake ${ }^{* *}$ and Kazuo Inoue ${ }^{* * *}$

\begin{abstract}
Model reference adaptive control system (MRACS) theory is an effective method for dealing with unknown systems. When an MRACS is constituted, current parameters and the state variables of the unknown plant are usually estimated to adjust control parameters. But there are some problems when they are estimated.

This paper presents a design method of an MRACS by an approximately inverse functional compensator. The system is constructed from a viewpoint of a learning control method and is based on an exact model matching (EMM) technique. The system designed by the proposed method can decrease the control error between the output of the plant and the reference model without estimation of the parameters and the state variables. The learning control method is used for the plant which can be controlled repeatedly. In the frequency zone of signals passing through the plant and the reference model, the approximately inverse functional compensator has inverse properties of the reference model.
\end{abstract}

\section{1. まえがき}

モデル規範形適応制御系 (MRACS) は未知プラント 亿対する制御方法としてすぐれており，実プラントにも 広く応用されている(1) 3). プラントの出力を規範モデル の出力に一致させるととを目的とした制御系は, Exact Model Matching (EMM) 系とよばれ, MRACSの基 礎となっている4). 規範モデルの近似的な逆系を用いた

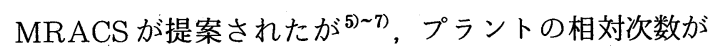
3 次以上の場合, フィードバックゲインを大きくすると 安定性が損なわれるためモデルマッチングが近似的にし か行なわ执かった。 そてで，状態フィードバックを用 いることによって安定性を損なうことなく EMM 系を

\footnotetext{
* 原稿受付 1990. 10. 4

** 立命館大学 大学院 理工学研究科 Graduate Course of Department of Electrical Engineering, Faculty of Science and Engineering, Ritsumeikan University ; Tojiin Kita-machi, Kita-ku, Kyoto 603, JAPAN

*** 立命館大学 理工学部 Department of Computer Science and Systems Engineering Faculty of Science and Engineering, Ritsumeikan University; ditto.

Key Words : MRACS, EMM, learning control method, robust control, approximately inverse functional compensator.
}

構成に, MRACSへの拡張を行なう報告がなされてい. $3^{8) \sim 10)}$. しかし, 状態フィードバックによる方法では プラントのパラメータや状態を推定しなければならず, システムが複雑になり, また状態推定に関する諸問題を 考慮に入れなければならない.

本論文では, 構成の簡単な近似逆関数補償 MRACS に学習制御方式を導入した連続時間 1 入出力 MRA.CS の構成法 ${ }^{11)}$ について述べる. 提案する構成法では, 試 行を通してプラント出力と規範モデルの出力との誤差 を零とするため, ハイゲイン手法を用いる必要がなく, プラントの相対次数が 3 次以上の場合にも安定性が保 障されるあのである. また, 内部に同定部むなく, 動 的補償器として状態観測器を用いるてともないため, システムの構成が簡単であり, 状態推定に関する諸問 題を考慮に入れる必要がない。なお，本論文で扱う近 似的な逆系とはシステムを通過する信号の周波数帯域 そおいて規範モデルの逆関数の特性を持つあののてとで ある12).

\section{2. 問題の記述}

制御対象として (1) 式で表わされる線形 1 入出力連続 
時間系を考える.

$$
\begin{aligned}
& Y(s)=W_{P}(s) U(s) \\
& W_{P}(s)=\frac{N_{P}(s)}{D_{P}(s)}=\frac{b_{m} s^{m}+\cdots+b_{0}}{s^{n}+\cdots+a_{0}} .
\end{aligned}
$$

制御対象 $W_{P}$ は可制御可観測, $N_{P}(s)$ は $m$ 次の安定 多項式でその最高次数の係数 $b_{m}$ は既知で, $D_{P}(s)$ は $n$ 次のモニック多項式, 次数 $n, m(n \geqq m)$ 之最大折点周 波数は既知であるとする. また，規範モデルについても 線形 1 入出力連続時間系で次式で表わされるあのとする.

$$
\begin{aligned}
& Y_{M}(s)=W_{M}(s) R(s) \\
& W_{M}(s)=\frac{N_{M}(s)}{D_{M}(s)}=\frac{b_{M m} s^{m}+\cdots+b_{M 0}}{s^{n}+\cdots+a_{M 0}}
\end{aligned}
$$

$W_{M}(s)$ の分子, 分母の次数はプラントと同じあのを 選び, $N_{M}(s)$ は $m$ 次の安定多項式, $D_{M}(s)$ は $n$ 次の モニック安定多項式とする. また, $R(s)$ は規範入力で ある. プラント出力 $y_{P}$ が規範モデルの出力 $y_{M}$ に漸近 的に一致するような適応入力 $u(t)$ を発生させるために, 補償要素として (5) 式で与えられるような規範モデルの 近似逆関数を用いる.

$$
H(s)=\frac{\beta}{W_{M}(s) D_{H}(s)}
$$

(5) 式に拈いて $\beta$ はフィードバックゲイン, $D_{H}(s)$ は, $H(s)$ をプロパーにするために付加された $(n-m)$ 次の安定多項式である.

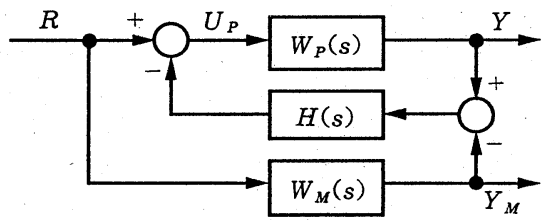

Fig. 1 Basic constitution of an exact model matching system by approximately inverse functional compensator

Fig. 1 は提案する制御系の構成図である. 乙の時, $Y(s)$ は次式のように表わされる. なお, 簡略化のため $D_{H}(s)$ などの $s$ の関数は $D_{H}$ と記す.

$$
\begin{aligned}
Y & =\frac{1+W_{M} H}{1+W_{P} H} W_{P} R \\
& =\frac{\left(D_{H}+\beta\right) N_{M} N_{P}}{N_{M} D_{P} D_{H}+\beta N_{P} D_{M}} R
\end{aligned}
$$

(6) 式において, $\beta \rightarrow$ 大とできれば $Y \rightarrow Y_{M}$ となり EMM を達成するてとができる. プラントの分母・分子 の次数差，つまり相対次数が 2 以下であれば，補償要素 の根を調整し， $\beta \rightarrow$ 大の場合にあ系全体を安定にする
ことができる. しかし, 相対次数が 3 以上の時には $\beta \rightarrow$ 大でシステムが不安定となってしまうために EMM が 達成できない12).

そこで, 1 試行前の誤差情報を用いた学習制御方式を 導入することによって, 相対次数が 3 以上の場合にも安 定性を損なうことなく，(1) 式で与えられるプラント出 力を (3) 式で与えられる規範モデルの出力に一致させる ための制御則を導出する ${ }^{11)}$.

\section{3. 学習制御方式を用いた MRACS の構成}

Fig. 2 は提案する制御系の構成図である. ただし, 有限時間内で同一の目標值のもとでの制御を繰り返すむ のとする. また，それぞれの試行に対する初期值は同じ 值とし, 目標值 $Y_{M}$ 抢よび規範入力 $R$ の周波数帯域は ある周波数 $\omega_{S}$ 以下であるとする. 試行を $i$ 回繰り返し た場合の制御入力 $U_{i}$ は

$$
\begin{aligned}
& U_{i}=U_{i-1}-H \cdot\left(Y_{i}-Y_{M}\right) \\
& Y_{i}=W_{P} U_{i}
\end{aligned}
$$

となる，乙れを整理すると，次の漸化式で与えられる制 御則を得る.

$$
\begin{aligned}
& U_{i}=\frac{U_{i-1}+W_{M} H R}{1+W_{P} H} \\
& U_{0}=R
\end{aligned}
$$

ここで $U_{i}, Y_{i}$ は $i$ 回目の試行の制御入力, プラント出 カである.（9）式の漸化式を解くと

$$
U_{i}=\left(\frac{1}{1+W_{P} H}\right)^{i}\left(1-\frac{W_{M}}{W_{P}}\right) R+\frac{W_{M}}{W_{P}} R
$$

となる. したがって, $i$ 回目の試行の出力 $Y_{i}$ は (11) 式 で表わされる.

$$
Y_{i}=\left(\frac{1}{1+W_{P} H}\right)^{i}\left(W_{P}-W_{M}\right) R+W_{M} R
$$

(11) 式に扔いて $t \rightarrow \infty$ に打ける安定条件は 2. で述べ たように，(6) 式の極が安定領域に収まっていることで ある.

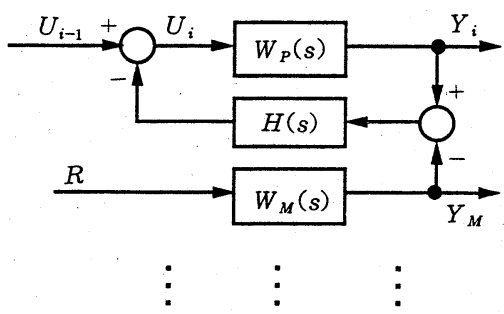

Fig. 2 A Constitution of MRACS by use of learning control method 
$D_{H}$ の最小折点周波数（ $\geqq$ 入信号の遮断周波数）を $\omega_{c}$ として, (12) 式のノルムの条件を満足するよう補償 要素を決定すれば, $\beta \rightarrow$ 大とするととなしに, 試行の 繰り返しによってプラント出力は (13) 式となり, 規範 モデルの出力に一致する. ただし，ノルムは $\|G(s)\|=$ $\max _{\omega \leq \omega_{c}}|G(j \omega)|$ と定義する.

$$
\begin{aligned}
& \left\|\frac{1}{1+W_{P} H}\right\|<1 \\
& \lim _{i \rightarrow \infty} Y_{i}=\left(\frac{1}{1+W_{P} H}\right)^{i}\left(W_{P}-W_{M}\right) R+W_{M} R \\
& =Y_{M}(s)
\end{aligned}
$$

つまり，(7) 式で与えられる制御則を用いれば，プラ ントのパラメータや状態の情報を用いることなく, 試行 の繰り返しと共にプラント出力が規範モデルの出力にマッ チングすることがわかる.（13）式における収束の速さ については, $\left|1+W_{P}(j \omega) H(j \omega)\right|$ が大きくなるにつれ， 指数関数的に速くなる.

\section{4. 解 析}

本章では提案した制御系の安定性と（12）式のノルム の条件についての解析を行なう. 相対次数が 2 以下の場 合は 2. で述べたように安定性を満足し， EMM を達成 させることができる. したがって，乙こでは相対次数が 3 以上の場合についての解析を行なう.

$D_{H}$ の最小折点周波数 $\omega_{c}$ を $W_{P}, W_{M}$ の最大折点周 波数より大きくとると, $W_{P}(j \omega) H(j \omega)$ のボード線図 (ゲイン図) は Fig. 3 のようになる. ここで, $\omega_{c}$ 以下の 周波数領域に掠て $\left|W_{P}(j \omega) H(j \omega)\right|>2$, またはその 位相角が, $-\pi / 2<\angle W_{P}(j \omega) H(j \omega)<\pi / 2$ となるよ うにフィードバックゲイン $\beta$ を与えられるので, (12) 式の条件を $\omega<\omega_{\mathrm{c}}$ の範囲で常に満足させることができ る.

また, 安定性については, 補償要素 $H$ が安定である ことから, $W_{P}$ の不安定な極の数と, $W_{P}(j \omega) H(j \omega)$ のナイキスト線図が点 $(-1,0)$ を反時計方向に回る回 数とが同じであれば,（11）式で表わされるシステムは 安定である. 提案したシステムでは, $W_{P}(j \omega) H(j \omega)$

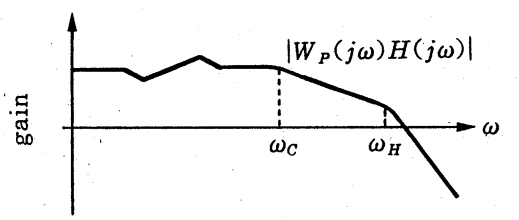

Fig. 3 Gain diagram of $W_{p}(s) H(s)$ when $\omega_{c}$ is much grater than cut-off frequency of the plant and the reference model
の構成要素である $W_{P}(j \omega) / W_{M}(j \omega)$ によって, 周波 数が $\omega_{c}$ に至るまでに, 点 $(-1,0)$ を $W_{P}$ の不安定極の 数だけ反時計方向に回る. したがって, $\omega_{c}$ 以上の周波 数領域に拈いて $W_{P}(j \omega) H(j \omega)$ のナイキスト線図が, 点 $(-1,0)$ を回らなければシステムは安定である. そ こてで, $D_{H}$ を次式のように与える.

$$
D_{H}=\frac{\left(s+\omega_{c}\right)\left(s+\omega_{H}\right)^{n-m-1}}{\omega_{c} \omega_{H}^{n-m-1}}
$$

$W_{P}(j \omega) / W_{M}(j \omega)$ の位相は高周波域では $2 \pi$ の倍数 となる. したがって, 周波数が $\omega_{c}$ に近づくと $W_{P}(j \omega)$ $H(j \omega)$ のベクトル軌跡は Fig. 4 のように位相角零度 の方向から原点に近づく.

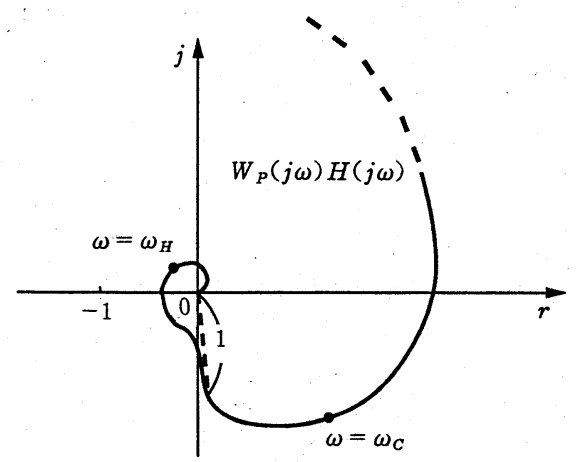

Fig. 4 Nyquist diagram of $W_{p}(j \omega) H(j \omega)$ when $\omega_{s}$ and $\omega_{H}$ are given by Eq. (15)

(14) 式のように $D_{H}$ を設定すれば, $\left(s+\omega_{c}\right)$ の項に よって $\omega_{c}$ 以上の周波数領域でゲインが減少する. $\omega_{H}$ を $\omega_{c}$ より十分大きく与えれば，位相がー $\pi$ に至るまで に $\left|W_{P}(j \omega) H(j \omega)\right|<1$ を満たすととができる. 上記 の十分条件は，（15）式のように $\omega_{c}, \omega_{H}$ を与えること である.（導出については付録参照)

$$
\omega_{H} \cdot \tan \frac{\pi}{2(n-m-1)}>\left|\beta \frac{b_{m}}{b_{M m}} \omega_{c}\right|
$$

この時, ゲインは単調に減少するため, $\omega>\omega_{c}$ の周 波数領域において $W_{P} H$ のベクトル軌跡は点 $(-1,0)$ を 回らない。つまり，上記のように $D_{H}$ を設定すれば本 システムは安定となる13).

また, プラントのパラメータが変動しても, 変動の範 囲が $\omega>\omega_{\mathrm{c}}$ において点 $(-1,0)$ を回らず， $\omega_{c}$ 以下の 周波数領域で $\left|W_{P}(j \omega) H(j \omega)\right|>2$ を満たす範囲内で あれば，提案した設計法によって $\mathrm{EMM}$ を達成できる.

(12) 式の条件と閉ループ系の安定性に関するスモー ルゲイン定理との関係については次のようである. ス モールゲイン定理は安定性に関する十分条件であるが, 
本研究では $W_{P}(s)$ が安定であるとは限らないなどスモ ールゲイン定理の適用ができない. しかし，本研究に おいては (14) 式，(15) 式のように $D_{H}(s)$ を与えるて とによって閉ループ系の安定性を確保しているため, $\left|W_{P}(j \omega) H(j \omega)\right|$ に関する条件は，スモールゲイン定 理の条件とは関係なく満足させることができる.

参考文献 14）ではノルムの条件を満足するために，あ る周波数以上の領域では学習させないという考えのもと に, 試行回数 $\rightarrow \infty$ での安定性を確保した. そのため, 学習させない周波数成分を多く含むとそれだけ多くの偏 差が残る、本論文では出力誤差を補償要素に通してやる ことによって，(12) 式のノルムの条件を満足させてや るととのできる周波数領域を目標值の持つ周波数成分よ り高い周波数まで移動させるという考えのあとで構成を 行なっている. したがって，目標値に含まれる周波数に 帯域制限がある場合については，本手法を用いてやるて とによって安定性を確保しつつ偏差を零にするてとがで きるが，参考文献 14）による方法では，そのような場合 にであ偏差が残る場合がある．また，システム通過信号 がステップ信号のようなすべての周波数を含んでいる場 合には，試行回数 $\rightarrow \infty$ とすることができないが，ノル 么の条件を満足する領域とそうでない領域の周波数成分 の多少を考慮に入れるととにより，ある程度の制御効果 が期待できる. その例をシミュレーションで示す.

\section{5. シミュレーション}

提案した制御系について，その有効性を確認するため, 数值シミュレーションを行なった，どの例に関してむ, 1 試行あたりの制御時間は $20 \mathrm{sec}$ である.

Fig. 5, Fig.6 はプラント, 規範モデルおよび補償要 素は伝達関数が次式で与えられるすのを用いたシミュレ ーション結果である.

$$
\begin{aligned}
W_{P}(s) & =\frac{1}{s^{2}+1.5 s+a} \\
W_{M}(s) & =\frac{4}{s^{2}+2 s+4} \\
H(s) & =\frac{s^{2}+2 s+4}{4} \frac{60 \cdot 300}{(s+60)(s+300)} \beta
\end{aligned}
$$

こでで,

$$
a=\left\{\begin{aligned}
10 & (0 \mathrm{sec} \leqq t \leqq 10 \mathrm{sec}) \\
-10 & (10 \mathrm{sec} \leqq t \leqq 20 \mathrm{sec})
\end{aligned}\right.
$$

である.（12）式のノルムの条件を満足させるため, 可 変フィードバックゲイン $\beta$ は $\beta=5$ とした.

また規範入力は

$$
r(t)=1
$$

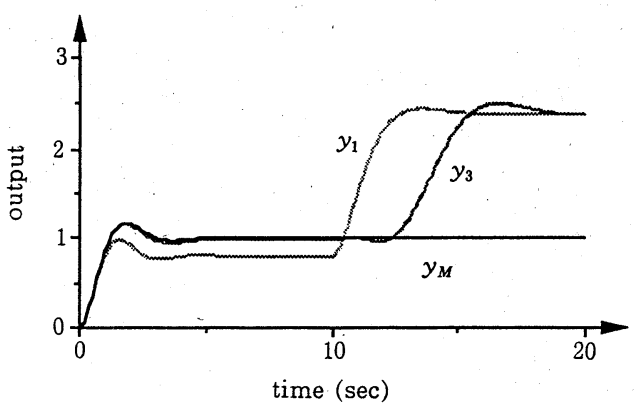

Fig. 5 The outputs of the controlled object at the 1 st trial and the $3 \mathrm{rd}$ trial when $r(t)$ is the unit step input

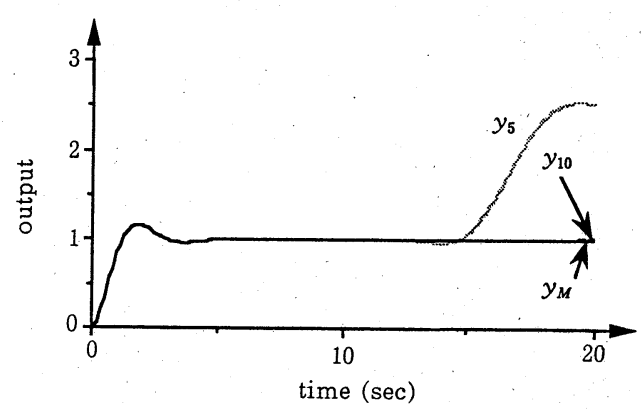

Fig. 6 The outputs of the controlled object at the 5 th trial and the 10 th trial when $r(t)$ is the unit step input

の単位ステップ関数でシステム通過信号がすべての周波 数を含んでいる例である.

ての数值シミュレーションにみられるように入力がス テップ入力のようなすべての周波数を含む場合でも, $D_{H}$ の調整によってある有限の試行回数までは規範モデ ルとプラントとの出力䛊差を減少させることができる.

Fig. 7, Fig. 8 はプラントの相対次数が 3 で, プラン ト，規範モデルおよび補償要素は伝達関数が次式で与え られるあのを用いたシミュレーション結果である.

$$
\begin{aligned}
W_{P}(s) & =\frac{1}{s^{3}+3 s^{2}+12 s+10} \\
W_{M}(s) & =\frac{30}{s^{3}+8 s^{2}+25 s+30} \\
H(s) & =\frac{\left(s^{3}+8 s^{2}+25 s+30\right) 30 \cdot 40^{2}}{30(s+30)(s+40)^{2}} \beta
\end{aligned}
$$

また，フィードバックゲイン $\beta$ は $\beta=1$ で，規範入 力は次の正弦波の和で与えられるあのを用いた.

$$
r(t)=\sin (0.1 \cdot \pi t)+\sin (0.2 \cdot \pi t)
$$

相対次数が 3 以上では, 状態フィードバックを用いな ければ EMM を達成できなかったが ${ }^{12)}$, Fig. 7, Fig.8 にみられるように，相対次数が 3 の場合であ本手法を用 


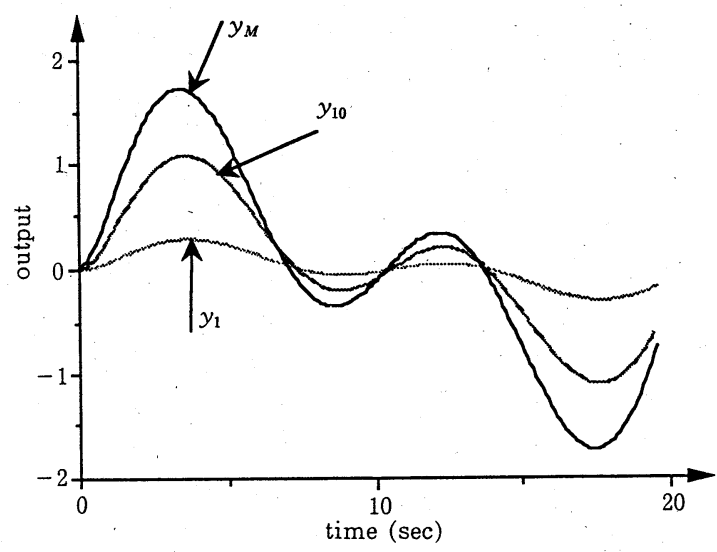

Fig. 7 The outputs of the controlled object at the 1 st trial and the 10 th trial when $r(t)=\sin (0.1 \pi t)+$ $\sin (0.2 \pi t)$

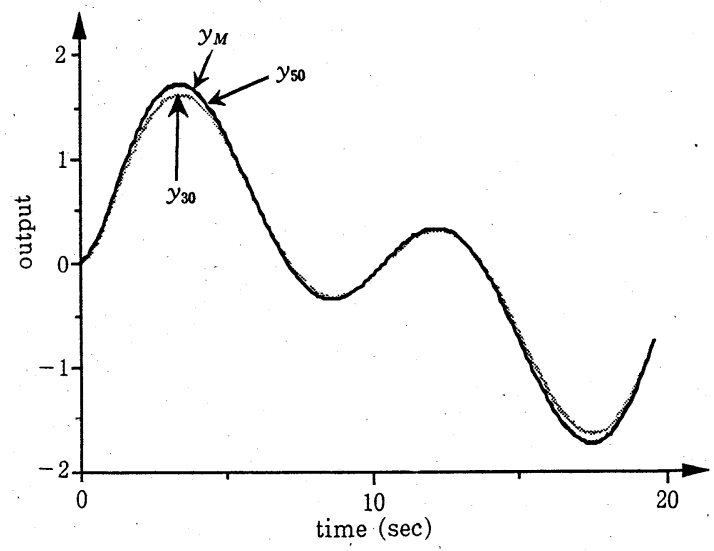

Fig. 8 The outputs of the controlled object at the 30 th trial and the 50 th trial when $r(r)=\sin (0.1 \pi t)+$ $\sin (0.2 \pi t)$

いるととにより EMM を達成できる.

\section{6. あとがき}

本論文では, 近似逆関数補償による連続時間モデル規 範形適応制御系に, 学習制御方式を用いるととによって EMM を達成する手法について示し，その特性を解析し た. 本構成法では, プラントパラメータの同定や状態推 定を行なう必要がないため, 同定や推定に伴う諸問題を 考虑に入れることなく簡単にモデル規範形適応制御系を 構成するととができる.

本手法は，外乱が存在する場合にあ外乱が試行を通し て同じ場合には有効であるが，一般に外乱が加わる場合 その加わり方が同じであるとは限らず，適切な学習効果 が得られない. したがって, 外乱抑制はシステム内のフィ ードバックループのみで行なわれるとととなる. 試行間
での外乱の入り方が同じでない場合や多变数系への応用 は今後の課題としたい.

\section{参考 文 献}

1) J. W. Gilbart and G. C. Winston : Adaptive Compensation for an Optical Tracking Telescope ; Automatica, Vol. 10, pp. 125 131 (1974)

2) J. Van Amerongen and A. J. Udink Ten Cate : Model Reference Adaptive Autopilots for Ships ; Automatica, Vol. 11, pp. 441 450 (1975)

3) B. Courtiol and I. D. Landau : High Speed Adaptation System for Controlled Electrical Drivers ; Automatica, Vol. 11, pp. 119 127 (1975)

4) 市川 : Exact Model Matching 手法に基づく適応制御系の 構成; 計測自動制御学会論文集, Vol. 20, No. 10, pp. 926 931 (1984)

5) 西村, 藤井, 井上 : 受動的適応制御系の設計 ; 制御工学, Vol. 10, No. 6, pp. 304 311 (1966)

6) 西村, 藤井, 井上 : 受動的適応制御系の設計 (II ) : 制御工 学, Vol. 11, No. 8, pp. 411 420 (1967)

7) 西村, 藤井, 井上 : 受動的適応制御系の設計一吕（受動的 適応制御系之自己適応制御系の比較）; 制御工学, Vol. 12, No. 3, pp. 128 136 (1968)

8) 田村, 井上 : 規範モデルの逆系を利用した制御系設計法一 exact model matching 手法に基づくシステム外乱除去と適 応制御系，むだ時間系への応用一; システムと制御，Vol. 31, No. 12 , pp. 889 895 (1987)

9) 田村：モデル規範形適応制御とセルフチューニングレギュ レータ; 計測と制御, Vol. 23, No. 5, pp. 428 432 (1984)

10) 新 : 適応制御; 数理科学, No. 255 , pp. $41 \sim 46$ (1984)

11）大場, 井上: 学習制御方式を用いた EMM 系の一構成法 ; 第 34 回システム制御情報学会研究発表講演会講演論文集, pp. 273〜274 (1990)

12) 井上, 大場, 川野, 井上: 受動的適応ループによる適応観 測器の構成 ; システム制御情報学会論文集, Vol. 2, No. 4, pp. 128〜134 (1989)

13）大場, 井上 : 学習制御方式を用いた近似逆関数補償 MRACS の一構成法 ; 第 33 回自動制御連合講演会, 1002, pp. 3 4 (1990)

14）美多, 加藤, 青木 : 反復制御とロボットアームの軌道制御 への応用; 計測自動制御学会論文集, Vol. 21, No. 11, pp. 1223 1230 (1985)

\section{付録}

$D_{H}$ の $\frac{\omega_{H}{ }^{n-m-1}}{\left(j \omega+\omega_{H}\right)^{n-m-1}}$ による位相の変化を $\phi$ とす

ると $\phi=-(n-m-1) \tan ^{-1}\left(\omega / \omega_{H}\right)$ となる.

また, $\phi>-(\pi / 2)$ の時には, $\tan ^{-1}\left(\omega / \omega_{H}\right)$ が単調 増加であることから

$$
\omega_{H} \cdot \tan \{\pi / 2(n-m-1)\}>\omega
$$

が成立する. $\omega_{c}<\omega<\omega_{H}$ の時, $\left|W_{P} H\right|<1$ を満たす ためには

$$
\begin{aligned}
\left|W_{P} H\right| & =\left|\beta \cdot \frac{N_{P} D_{M}}{D_{P} N_{M}} \cdot \frac{\omega_{c}}{\left(j \omega+\omega_{c}\right)} \frac{\omega_{H}^{n-m-1}}{\left(j \omega+\omega_{H}\right)^{n-m-1}}\right| \\
& <\left|\beta \cdot \frac{b_{m}}{b_{M m}} \frac{\omega_{c}}{\omega}\right|<1
\end{aligned}
$$


398

システム制御情報学会論文誌 第 4 巻 第10 号 (1991)

を満たせばよい。したがって，(15)'式と (15)”式より

(15)" 式, さらに (15) 式の十分条件が得られる.

$$
\begin{aligned}
& \omega_{H} \cdot \tan \frac{\pi}{2(n-m-1)}>\omega>\left|\beta \frac{b_{m}}{b_{M m}} \omega\right| \\
& \omega_{H} \tan \frac{\pi}{2(n-m-1)}>\left|\beta \frac{b_{m}}{b_{M m}} \omega_{c}\right|
\end{aligned}
$$

$-6-$ 